\title{
Article \\ Biomechanical Comparison of a Novel Implant and Commercial Fixation Devices for AO/OTA 43-C1 Type Distal Tibial Fracture
}

\author{
Shun-Ping Wang 1,2, Kun-Jhih Lin ${ }^{3}$, Cheng-En Hsu ${ }^{1,2}$, Chao-Ping Chen ${ }^{1,4}$, Cheng-Min Shih 1,5,6 \\ and Kang-Ping Lin ${ }^{3,7, *}$ \\ 1 Department of Orthopedics, Taichung Veterans General Hospital, Taichung 407, Taiwan; \\ wsp0120@vghtc.gov.tw (S.-P.W.); Jacobhe2001@vghtc.gov.tw (C.-E.H.); cpchen@vghtc.gov.tw (C.-P.C.); \\ 10chengmin@vghtc.gov.tw (C.-M.S.) \\ 2 Sports Recreation and Health Management Continuing Studies-Bachelor's Degree Completion Program, \\ Tunghai University, Taichung 407, Taiwan \\ 3 Technology Translation Center for Medical Device, Chung Yuan Christian University, Taoyuan 320, Taiwan; \\ d40104007@ym.edu.tw \\ 4 Department of Acupressure Technology, Jen-Teh Junior College of Medicine, Nursing and Management, \\ Miaoli 356, Taiwan \\ 5 Department of Physical Therapy, HungKuang University, Taichung 433, Taiwan \\ 6 Department of Biological Science and Technology, National Chiao Tung University, Hsinchu 300, Taiwan \\ 7 Department of Electrical Engineering, Chung Yuan Christian University, Taoyuan 320, Taiwan \\ * Correspondence: kplin@cycu.edu.tw; Tel.: +886-3-265-4845
}

check for

updates

Citation: Wang, S.-P.; Lin, K.-J.; Hsu, C.-E.; Chen, C.-P.; Shih, C.-M.; Lin, K.-P. Biomechanical Comparison of a Novel Implant and Commercial Fixation Devices for AO/OTA 43-C1 Type Distal Tibial Fracture. Appl. Sci. 2021, 11, 4395. https://doi.org/ 10.3390/app11104395

Academic Editors: Zimi Sawacha and Ana Paula Betencourt Martins Amaro

Received: 23 February 2021

Accepted: 5 May 2021

Published: 12 May 2021

Publisher's Note: MDPI stays neutral with regard to jurisdictional claims in published maps and institutional affiliations.

Copyright: (c) 2021 by the authors. Licensee MDPI, Basel, Switzerland. This article is an open access article distributed under the terms and conditions of the Creative Commons Attribution (CC BY) license (https:// creativecommons.org/licenses/by/ $4.0 /)$.
Abstract: This study compares the novel Asia Distal Lateral Tibial Locking Plate mechanical stability to that of the current anterolateral and medial tibial plates based on finite element analysis. Four-part fracture fragment model of the distal tibia was reconstructed using CAD software. A load was applied to simulate the swing phase of gait. The implant stress and the construct stiffness were compared. The results of the anterolateral plate and the medial plate were similar and the displacement values were determined lower than those in the medial plate. In the simulated distal tibia fracture, the Aplus Asia Distal Lateral Tibial Locking Plate and medial distal tibial plate tibia fixations will lead to a stiffer bone-implant construct compared to the anterolateral distal tibial plate. Moreover, the stress in the Aplus Asia Distal Lateral Tibial Locking Plate was lower than those for the medial distal tibial plate and anterolateral bone plates. The Aplus Asia Distal Lateral Tibial Locking Plate has better stabilization and is an anterolateral plate that avoids more soft tissue damage than other bone plates. The Aplus Asia Distal Lateral Tibial Locking Plate could be one of a suitable design in tibia distal fracture fixation.

Keywords: distal tibial fracture; anterolateral plates; medial plate

\section{Introduction}

The treatment of distal tibial fractures can be challenging for a surgeon, which has high infection rate, wound healing complications, and post-traumatic arthritis. In an effort to preserve the soft tissue and envelope perform the appropriate osseous reconstruction, multiple surgical approaches and fixation strategies have been developed. The anterolateral plating and medial plating were two major options for plate osteosynthesis via a variety of surgical approaches [1-3]. Previous studies demonstrated the biomechanical advantages of the medial plate; however medial plating would cause soft tissue problems ranging from skin irritation to necrosis $[3,4]$. The superficial peroneal nerve is better visualized in the anterolateral approach [5]. Despite these advantages, anterolateral plating fixation stability may be inferior to medial plating in the treatment of distal tibial fractures $[6,7]$.

The anterolateral plates analyzed in the biomechanical literatures [6,7] are L-shaped, with a $3.5 \mathrm{~mm}$ LCP Anterolateral Distal Tibia Plate (DePuy Synthes, Paoli, PA, USA) and Distal Lateral Tibial Locking Plate (Zimmer Inc, Warsaw, Indiana). The articular part of the 
anterolateral plate is capable of accepting only four screws, whereas the medial plates have six or nine screws to purchase the bone fragments. Although the anterolateral the medial implants are fixed at different positions and have different geometric configurations, it can be speculated that more screws in the medial plate contribute to better stability compared to the anterolateral plate. In a plate/bone mapping study for a large cohort of pilon fractures [8], the authors suggested no current anterolateral distal tibial locking plate was found to be superior to the others in capturing all OTAC3 pilon fragment fracture lines. Sohn et al. [9] recently evaluated anterolateral fragment reconstruction with the anatomically precontoured locking plate in the pilon fracture. Sohn et al. concluded that a newly designed anterolateral distal tibia plate may be necessary when the commonly used distal tibia locking plate fails to cover the anterolateral fragment.

In order to obtain better fragment catching and anatomical reduction, a low profile, multi-screw fixation plate has recently been introduced. This plate allows for screw insertion trajectory versatility to maximize fragment capture. However, it is unknown whether the novel implant can provide sufficient fixation strength compared to the medial tibial plating. This study compares the mechanical stability of the novel ADLT (Asia Distal Lateral Tibial Locking Plate) to the current anterolateral and medial tibial plates based on finite element analysis. The mechanical stability was defined that had lower fragment bone displacement and larger axial stiffness on tibia after implantation.

\section{Materials and Methods}

3D intact model of the tibia geometry was reconstructed from CT images of a healthy 58-year-old Chinese male. This subject doesn't have any bone tissue or soft tissue disease. The slice thickness of the CT scan image (Light Speed VCT, GE Medical System, General Electric Company, USA) is $1.25 \mathrm{~mm}$, and in-place resolution of $512 \times 512$ pixels. IRB approval of this study is from Show Chwan Memorial Hospital (No. 1021004). The 3D tibia model via the cortical shell and cancellous core were reconstructed by a CAD software, PTC Creo 2.0 (Parametric Technologies Corp., Needham, MA, USA). The cortical thickness was approximately $2.5 \mathrm{~mm}$ and $4.5 \mathrm{~mm}$ in medial and post wall of this tibial site, respectively. Simulated AO/OTA 43-C1 type fracture was used in this study [10].1 mm gap was simulated between bone fragments (Figure 1) [11].
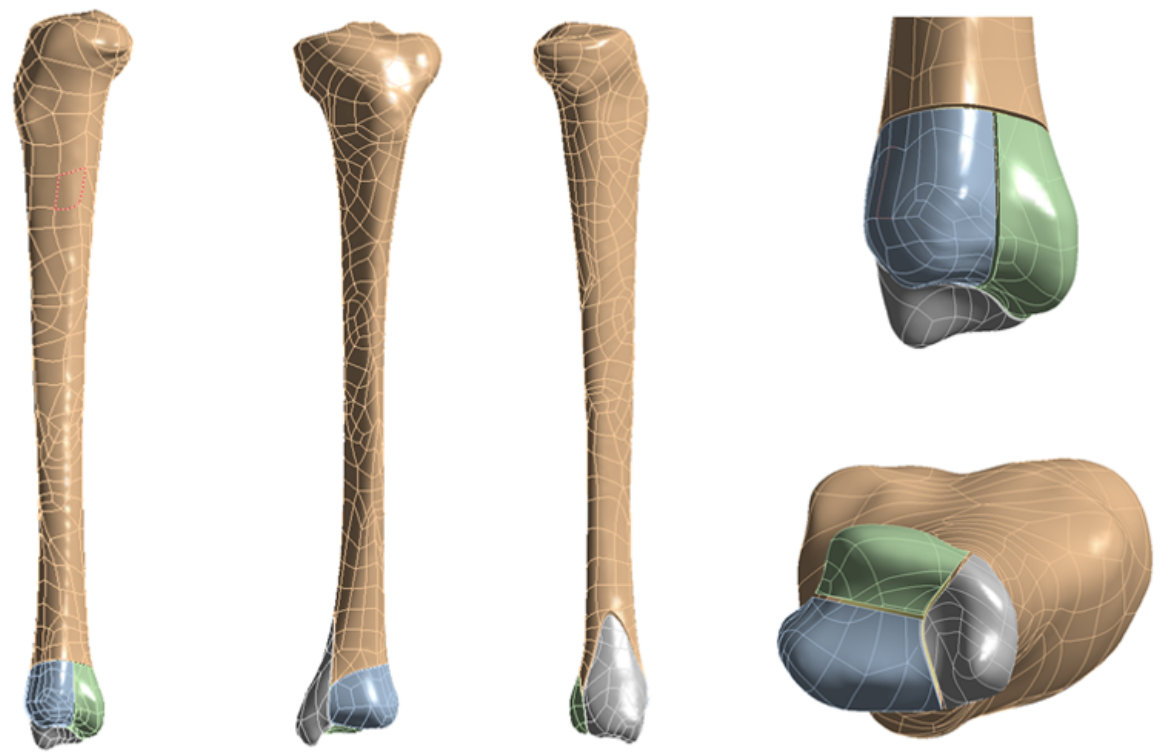

Figure 1. The AO/OTA 43-C1 type fracture tibia bone model.

Three distal tibial plates were involved in the current study. They are the novel ADLT plate (A Plus Biotechnology Co. Ltd., New Taipei City, Taiwan) and two common implants: 
$3.5 \mathrm{~mm}$ LCP anterolateral distal tibial plate (Synthes $3.5 \mathrm{~mm}$ ADT) and $3.5 \mathrm{~mm}$ LCP medial distal tibial plate (Synthes $3.5 \mathrm{~mm}$ MDT) (Depuy Synthes, Paoli, PA, USA). All plate models were affixed to the tibial shaft with six 3.5-mm locking screws. For the articular fixation, the Aplus ADLT was designed with four distal 2.7-mm locking screws as rafting fixation support, two diagonal 2.7-mm screws for posterior fragment capture, and two 2.7-mm strut screws for construct support (Figure 2). The Synthes $3.5 \mathrm{~mm}$ ADT has only four $3.5-\mathrm{mm}$ locking screws in the distal head (Figure 2b) while it accepts six 3.5-mm locking screws in the Synthes $3.5 \mathrm{~mm}$ MDT (Figure 2c).
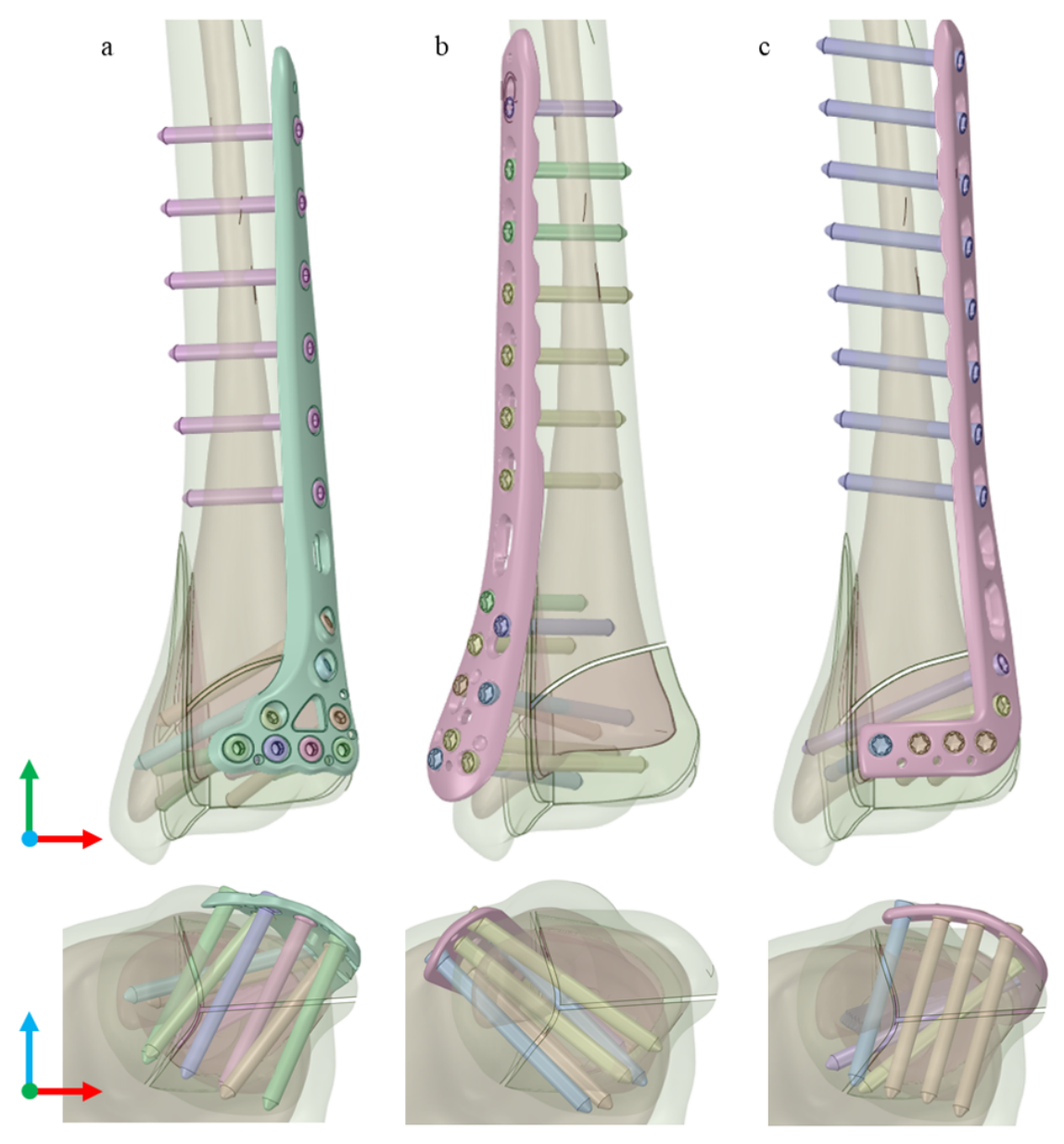

Figure 2. Three different type distal tibia plates were implanted on a distal tibia (a) Aplus ADLT bone plate, (b) Synthes ADT bone plate, and (c) Synthes MDT bone plate.

The ANSYS Workbench 19 (ANSYS Inc., Canonsburg, PA, USA) was used for computational analysis. A convergence test was performed based on total strain energy. For the convergence test, a new tibia FE model with more element and node numbers were calculated and the presented FE model results were compared with those from the new FE model. After convergence test completion, each design model has 511,899 elements on average. Due to the bone plate and threaded screw hole complex geometry, the mesh consists of only tetrahedral elements. The thread on the plates and screws was simplified as a smooth outer surface.

For load and boundary conditions in each group, the distal end of the tibia was fully constrained in all degrees of freedom. A three-point crutch gait was used for the load condition. Due to the inability of normal walking immediately after operation, the injured leg seldom contacts the ground when a pair of crutches are used. However, muscle forces are generated during the gait swing phase [12]. The adjacent muscles such as the gastrocnemius and soleus generate about 10 percent of the body weight in a tibia when 
a leg is in the swing phase in a normal gait cycle [13]. Normal body weight of an adult is $70 \mathrm{~kg}$, and 10 percent of the body weight $(70 \mathrm{~N})$ was applied to the tibial plateau [14]. FEA model was assumed as isotropic and linear elastic materials. The material properties of Young's modulus and Poisson's ratio assigned in the FE models are summarized in Table 1 [15]. A frictional contact behavior was defined between the fracture fragments with a coefficient of friction of 0.2 for possible contact after loading. Friction coefficient between the bone-plate interactions was 0.42 [16] whereas full constraints were applied between the surrounding bone and screws, and between the screw hole of the plate and the screw head to simulate tightened locking. Each group was compared in terms of the maximum von Mises stress in each plate and the stiffness of the plate-bone construct. The construct stiffness was derived from the load and vertical displacement data.

Table 1. Material properties of the models.

\begin{tabular}{ccc}
\hline Model Part & Young's Modulus (Mpa) & Poisson's Ratio \\
\hline Cortical bone & 17,500 & 0.3 \\
Cancellous bone & 1500 & 0.12 \\
Titanium alloy (Plate and screw) & 110,000 & 0.3 \\
\hline
\end{tabular}

\section{Results}

The Aplus ADLT stress distribution, Synthes $3.5 \mathrm{~mm}$ ADT and Synthes $3.5 \mathrm{~mm}$ MDT locking plates are shown in Figure 3. Table 2 summarize the comparison between fixation with anterolateral (ATL), the medial distal tibia (MDT) and Asia Distal Lateral Tibial (ADLT) plate fixation. In the finite element analysis, the maximum von Mises stress on three different bone plates were $144.15 \mathrm{MPa}, 181.00 \mathrm{MPa}$ and $228.82 \mathrm{MPa}$, respectively. The Aplus ADLT plate has the smallest maximum von Mises stress than $3.5 \mathrm{~mm}$ ADT and $3.5 \mathrm{~mm}$ Synthes MDT locking plates.

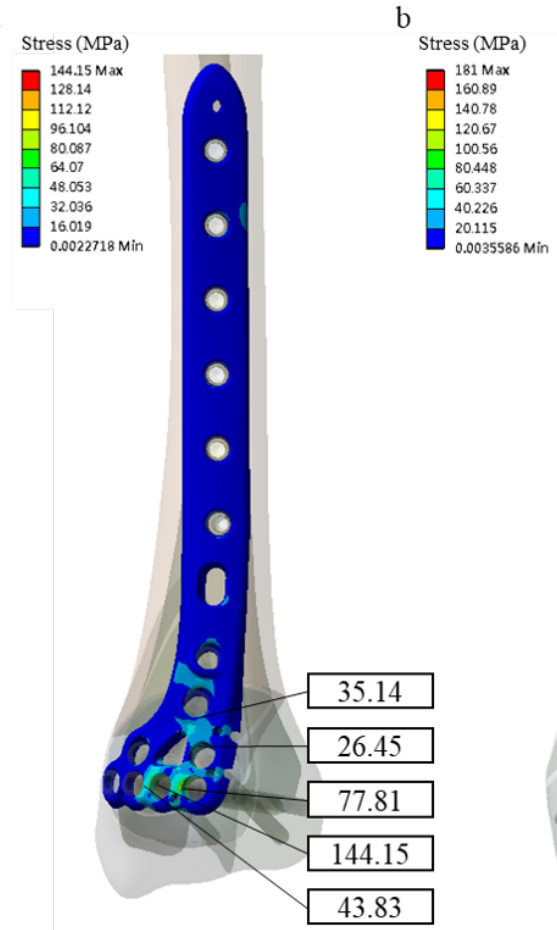

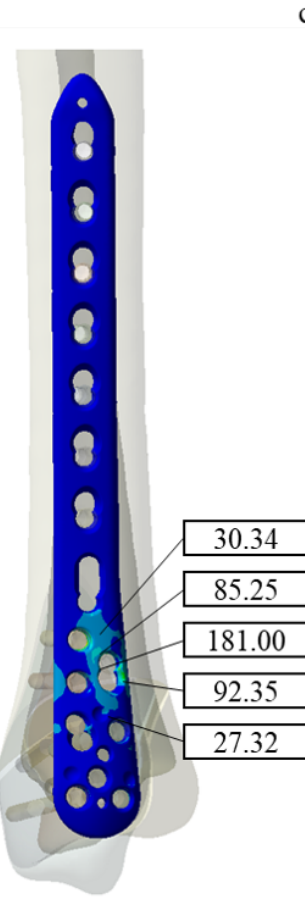

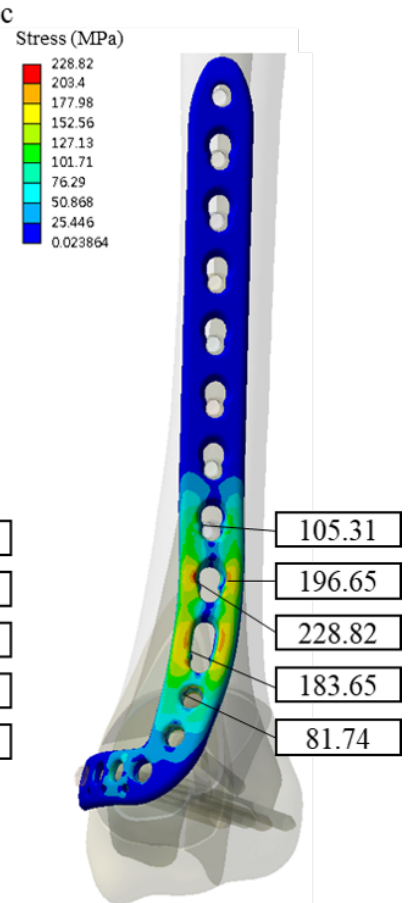

Figure 3. The von Mises stress distribution for three different bone plates and maximum von Mises stress around the screw hole. (a) Aplus ADLT bone plate, (b) Synthes $3.5 \mathrm{~mm}$ ADT bone plate, and (c) Synthes $3.5 \mathrm{~mm}$ MDT bone plate. 
The displacement in $\mathrm{Z}$ axis of the Aplus ADLT, Synthes $3.5 \mathrm{~mm}$ ADT and Synthes $3.5 \mathrm{~mm}$ MDT locking plates was shown in Figure 4. The fracture surface displacements in the $\mathrm{Z}$ axis were $0.0575 \mathrm{~mm}, 0.0444 \mathrm{~mm}$, and $1.3433 \mathrm{~mm}$, respectively. The $\mathrm{Z}$ axis of Aplus ADLT bone plate displacement was similar to that of Synthes $3.5 \mathrm{~mm}$ MDT, and below half that of Synthes $3.5 \mathrm{~mm}$ ADT locking plates. The axial stiffness were $1219.51 \mathrm{~N} / \mathrm{mm}$ in Aplus ADLT, $1576.58 \mathrm{~N} / \mathrm{mm}$ in Synthes $3.5 \mathrm{~mm}$ MDT, and $52.12 \mathrm{~N} / \mathrm{mm}$ in Synthes $3.5 \mathrm{~mm}$ ADT, respectively. The Aplus ADLT bone plate stiffness was similar to that of Synthes $3.5 \mathrm{~mm}$ MDT, and larger than Synthes $3.5 \mathrm{~mm}$ ADT locking plates significantly.
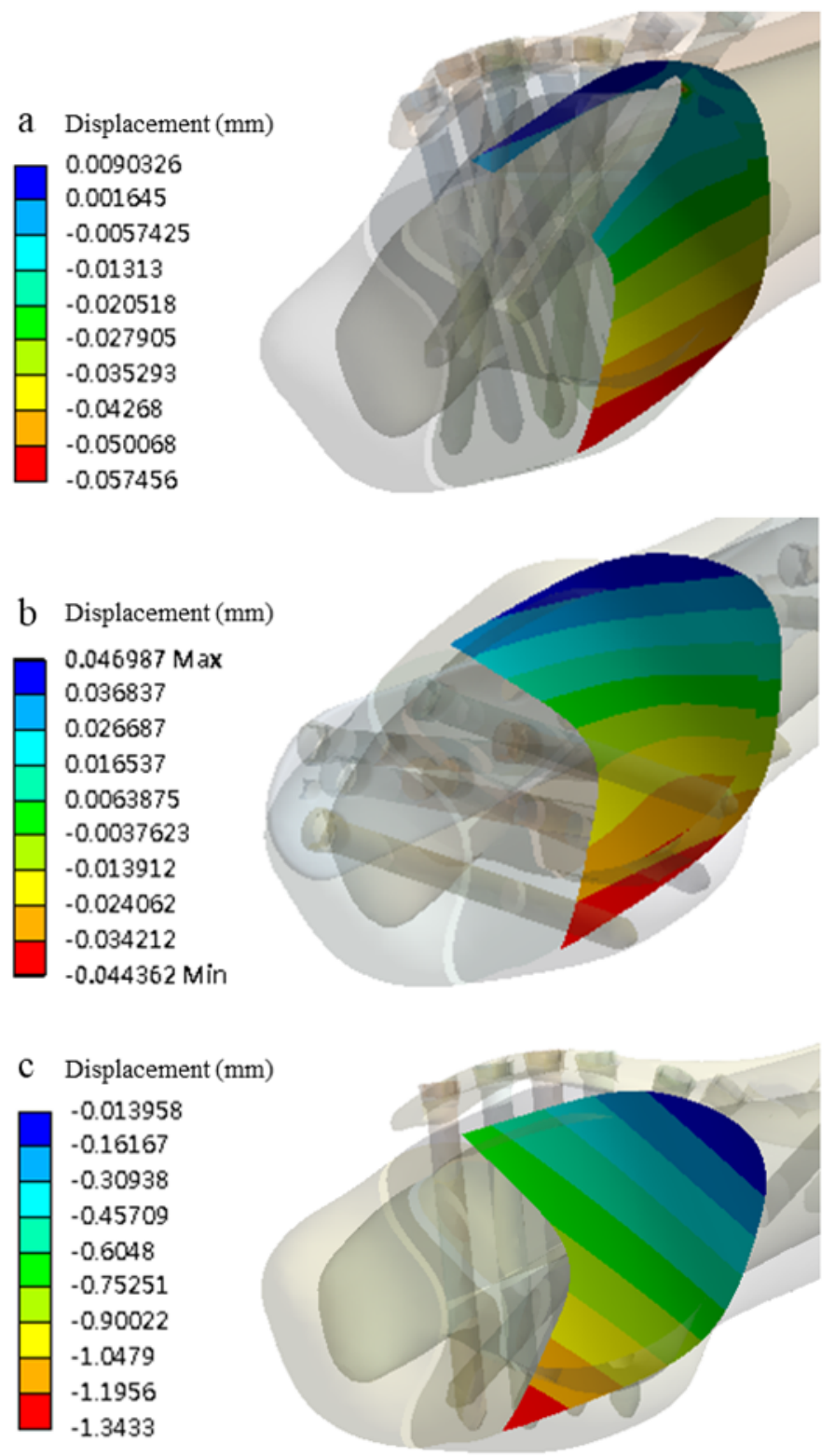

Figure 4. The z-axis tibia fracture surface displacement (a) Aplus ADLT bone plate groups, (b) Synthes $3.5 \mathrm{~mm}$ ADT bone plate groups, and (c) Synthes $3.5 \mathrm{~mm}$ MDT bone plate groups. 
Table 2. Comparison between fixation with anterolateral (ATL), the medial distal tibia (MDT) and Asia Distal Lateral Tibial (ADLT) plate fixation.

\begin{tabular}{ccc}
\hline Bone Plate Type & Maximum Bone Plate von Mises Stress (MPa) & Stiffness (N/mm) \\
\hline ADT & 228.82 & 52.12 \\
MDT & 181.00 & 1576.58 \\
ADLT & 144.15 & 1219.51 \\
\hline
\end{tabular}

\section{Discussion}

A pilon fracture is a type of break that occurs at the distal end of the tibia (shinbone) and involves the ankle joint weight-bearing surface. Its common cause is high-energy impact and is accompanied with severe soft tissue injuries. In most cases the soft tissue injury clinical manifestations are prolonged, with peak edema usually occurring 3 to 5 days after the injury. Mingo-Robinet et al. [17] and Bartonícek et al. [18] confirmed that posterior malleolus fracture anatomical reduction plays an important role in ankle joint stability. The pilon fracture treatment goals are articular surface and distal tibial alignment anatomical restoration while preserving the tenuous soft tissue envelope. Non-invasive surgical articular surface anatomical reduction is difficult to achieve [19]. Surgical treatment is an effective tool to reduce fragmented bone and restore the tibia stability, but achieves minimal to results for soft tissue damage. A variety of surgical approaches have been described to provide adequate plafond fracture line visualization during internal fixation while respecting the soft tissue biology [20].

Better understanding of soft tissue role in fracture repair has led to the development of minimally invasive plating techniques and low profile contoured plates. Similarly, soft tissue envelope evaluation became one of the major determinants for the surgical strategy, the surgeon's preference and together with fracture pattern. Clinically, varied bone plate systems were developed, to reduce and fix the fragmented bone. The bone plate system can be classified as the anterolateral and medial implants according to different set orientation. Raja et al. [6] compared the anterolateral (ADT) and medial distal tibia (MDT) locking plate stability in treating complex distal tibial fractures. The results show that the MDT provided better stability compared to the Synthes $3.5 \mathrm{~mm}$ ADT. Similar result was found in this present study, the Synthes $3.5 \mathrm{~mm}$ ADT plate have larger $\mathrm{Z}$ axis displacement than the Synthes $3.5 \mathrm{~mm}$ MDT and Aplus ADLT plates. The Aplus ADLT bone plate stiffness was similar to that of MDT, and larger than ADT locking plates significantly. The Synthes $3.5 \mathrm{~mm}$ MDT and Aplus ADLT have better stabilization than the Synthes $3.5 \mathrm{~mm}$ ADT. Lee et al. [21] compared medial and anterolateral distal tibia fracture plating with ORIF. The results of both groups were similar in respect to the malunion rate, functional score, union rate, injury mechanism, range of ankle motion, operative time and both medial and lateral plating achieved good functional outcomes with low malunion rate. However, the anterolateral plating group had a lower complication and fewer hardware issues. Furthermore, the subcutaneous tissue on the medial distal tibia is thin, and medial anatomic plates on the distal medial side of the tibia cause soft tissue issues [22].

The present study compared implant fracture construct stability and the effectiveness of Synthes $3.5 \mathrm{~mm}$ ADT, Synthes $3.5 \mathrm{~mm}$ MDT versus Aplus ADLT plate for the repair of complex distal tibia fracture. Maximum von Mises stress data obtained from the stress distribution pattern in bone plate and the amount of bony fragment displacements suggest that the Aplus ADLT is superior to the Synthes $3.5 \mathrm{~mm}$ ADT and Synthes $3.5 \mathrm{~mm}$ MDT. The fragmented bone fixation depends on the bone plate placement position. This will affect the structure stabilization. MacLeod et al. demonstrate that larger bridging spans increase interfragmentary movement without substantially increasing plate stress [23]. Tommaso et al. indicated that screw orientation affects the pressure distribution at the bone/screw interface [24]. Besides, screw diameter and number of screws play an important role. In this present, the Synthes $3.5 \mathrm{~mm}$ ADT plate have largest $\mathrm{Z}$ axis displacement than Synthes $3.5 \mathrm{~mm}$ MDT and Aplus ADLT plate. The result was led using different types and 
numbers of bone screws. Bone screws of the same diameter and length were employed to fix the fragmented bone in each bone plate model. Six bone screws were implanted at the bone plate proximal side. The difference with another bone plate, Synthes $3.5 \mathrm{~mm}$ ADT applied just six screws to fix the fragmented bone. Aplus ADLT and Synthes $3.5 \mathrm{~mm}$ MDT implanted eight bone screws at bone plate distal side. The difference between Aplus ADLT and Synthes $3.5 \mathrm{~mm}$ MDT include the implanted position and the geometrical configurations except for the number of screws. In addition, the opposite screw insertion technology have the potential advantage in the stresses on the bone plate and screws [25].

In this study, the Aplus ADLT bone plate system has minimum VMS stress in the plate and bone displacement Z-axis. The Aplus ADLT has these advantages included below; the lateral bone plate can avoid the soft tissue injury, triangular and anatomical plate design at the bone plate distal side. It has maximum rate in covering the bone surface. It is a locking plate design, although there may be issues such as fragment rotational instability, this situation could not be simulated in this study. The use of locking head screws, in addition to the ligamentotaxis effect of the surrounding tissue, may have overcome this issue. It is well established that locking screws have larger pullout mechanism than conventional thereby maintaining the bone-implant construct stability [26]. Most stress around the screw hole of the ADT were higher than $100 \mathrm{MPa}$ while the stress in many regions of the ADLT and MDT was under than $50 \mathrm{MPa}$, indicating the ADT might have more possibility of plate breakage during rehabilitation period. It was noted that von Mises stress was concentrated at the bend of the ADT and the MDT, which could be explained by leverage of load transmitted from the distal screws. Interestingly, the location of stress concentration for the ADLT was at the articular of the implant, meaning the implant design could provide anti-bending effect. The screw hole placement in the articular part of the ADLT features a triangle fixation configuration for fragment capture and two struct screws to resist the external force. These may contribute to high resistance to plate bending during loading. Consequently, we suggested that the newly designed implant, ADLT could be an alternative option for the treatment of the tibial pilon fractures. The Aplus ADLT could offer the similar stiffness with MDT plate and better than ALT plate. Therefore, the Aplus ADLT could be one of a suitable design in tibia distal fracture fixation.

Several limitations were observed in this study. The plate-bone constructs were examined under one loading and boundary condition based on previous publications $[6,14,27]$. In this present study, only one dimension was analyzed, the different tibia dimension was included to evaluate in further study. As we know, this simulated situation is certainly not representative of all physiological environment. Further development of new model to simulate more physiological conditions is necessary for future researches such as the evaluation of the risk of implant failure and the mechanics between implant-bone interfaces and the dynamic loading condition. The dynamic loading enhances the growth factors reaction [28]. The ADLT is a new implant expected to provide adequate stability for fracture fixation as the medial distal tibial plate (MDT) do. The lowest biomechanical requirement for a bone plate is to assure the initial stability after the fracture fixation. To evaluate the strength of the ADLT and compare with other commercialized implants, further biomechanical test is necessary to evaluate the ultimate strength of the bone-plate construct and the fatigue properties. In addition, further simulations to analyze the effect of the screw positioning on the fixation stability for this kind of fracture type are interesting in surgical field, especially for the novel ADLT plate design. Moreover, fracture configuration is also shown to be one type fracture mode to be used for fracture fixation. This study made use of known some parameters and deduced information based on previous studies [10,29-31] Furthermore, biomechanical testing may be necessary to provide more information. Finite element modeling was another limitation. Although it is known to be a good choice for biomechanical analysis, cadaver bone studies would provide stronger conclusions. 


\section{Conclusions}

This biomechanical study investigated the effect of three different bone plate implantation methods after tibial distal pilon fracture reduction using computed methods. The study results show that tibia Aplus ADLT and Synthes $3.5 \mathrm{~mm}$ MDT fixation methods will lead to a stiffer bone-implant construct compared Synthes $3.5 \mathrm{~mm}$ ADT. Moreover, the stress in the Aplus ADLT plate was lower than that for the Synthes $3.5 \mathrm{~mm}$ MDT and Synthes $3.5 \mathrm{~mm}$ ADT bone plates. The Aplus ADLT has better stabilization and is an anterolateral plate that avoids more soft tissue damage than the other bone plates. The Aplus ADLT could be a more suitable tibia distal fracture fixation design.

Author Contributions: S.-P.W. and K.-J.L. contributed to the conception and design of the study. K.-J.L. conducted the computational analysis. S.-P.W., K.-J.L., C.-E.H., C.-P.C. and C.-M.S. contributed to the data analysis and the interpretation of the data. S.-P.W. and K.-J.L. drafted the article. K.-P.L. critically reviewed and commented on the manuscript. All authors have read and agreed to the published version of the manuscript.

Funding: This research received no external funding.

Data Availability Statement: The data presented in this study are available on request from the corresponding author. The data are not publicly available due to ethical restrictions.

Conflicts of Interest: The authors declare no conflict of interest.

\section{References}

1. Oh, C.W.; Kyung, H.S.; Park, I.H.; Kim, P.T.; Ihn, J.C. Distal tibia metaphyseal fractures treated by percutaneous plate osteosynthesis. Clin. Orthop. Relat. Res. 2003, 408, 286-291. [CrossRef] [PubMed]

2. Collinge, C.; Sanders, R.; DiPasquale, T. Treatment of complex tibial periarticular fractures using percutaneous techniques. Clin. Orthop. Relat. Res. 2000, 375, 69-77. [CrossRef] [PubMed]

3. Helfet, D.L.; Shonnard, P.Y.; Levine, D.; Borrelli, J., Jr. Minimally invasive plate osteosynthesis of distal fractures of the tibia. Injury 1997, 28, A42-A48. [CrossRef]

4. Redfern, D.J.; Syed, S.U.; Davies, S.J. Fractures of the distal tibia:minimally invasive plate osteosynthesis. Injury 2004, 35, 615-620. [CrossRef] [PubMed]

5. Deangelis, J.P.; Deangelis, N.A.; Anderson, R. Anatomy of the superficial peroneal nerve in relation to fixation of tibia fractures with the less invasive stabilization system. J. Orthop. Trauma 2004, 18, 536-539. [CrossRef]

6. Aizat, R.M.; Kadir, M.R.A.; Ab Rahman, S.; Md Shihabudin, T.M.T.; Robson, N.; Kamarul, T. Biomechanical Comparative Analyses Between the Anterolateral and Medial Distal Tibia Locking Plates in Treating Complex Distal Tibial Fracture: A Finite Element Study. J. Med. Imaging Health Inform. 2013, 3, 532-537. [CrossRef]

7. Pirolo, J.M.; Behn, A.W.; Abrams, G.D.; Bishop, J.A. Anterolateral Versus Medial Plating of Distal Extra-articular Tibia Fractures: A Biomechanical Model. Orthopedics 2015, 38, e760-e765. [CrossRef] [PubMed]

8. Aneja, A.; Luo, T.D.; Liu, B.; Domingo, M.; Danelson, K.; Halvorson, J.J.; Carroll, E.A. Anterolateral distal tibia locking plate osteosynthesis and their ability to capture OTAC3 pilon fragments. Injury 2018, 49, 409-413. [CrossRef] [PubMed]

9. Sohn, H.S.; Oh, J.K.; Yang, H.S.; Kim, H.R. Anatomically Precontoured Locked Plates in Pilon Fractures: A Computed Tomography Based and Cadaveric Study. Indian J. Orthop. 2018, 52, 665-671.

10. Marsh, J.L.; Slongo, T.F.; Agel, J.; Broderick, J.S.; Creevey, W.; Decoster, T.A.; Prokuski, L.; Sirkin, M.S.; Ziran, B.; Henley, B.; et al. Fracture and dislocation classification compendium-2007: Orthopaedic Trauma Association classification, database and outcomes committee. J. Orthop. Trauma 2007, 21, S1-133. [CrossRef] [PubMed]

11. Stoffel, K.; Dieter, U.; Stachowiak, G.; Gächter, A.; Kuster, M.S. Biomechanical testing of the LCP-how can stability in locked internal fixators be controlled? Injury 2003, 34, B11-9. [CrossRef] [PubMed]

12. Anglen, J.O. Early outcome of hybrid external fixation for fracture of the distal tibia. J. Orthop. Trauma 1999, 13, 92-97. [CrossRef] [PubMed]

13. Anderson; C, F.; Pandy, M.G. Static and dynamic optimization solutions for gait are practically equivalent. J. Biomech. 2001, 34, 153-161. [CrossRef]

14. Kim, S.H.; Chang, S.H.; Son, D.S. Finite element analysis of the effect of bending stiffness and contact condition of composite bone plates with simple rectangular cross-section on the bio-mechanical behaviour of fractured long bones. Compos. Part B Eng. 2011, 42, 1731-1738. [CrossRef]

15. Zhang, Y.K.; Wei, H.W.; Lin, K.P.; Chen, W.C.; Tsai, C.L.; Lin, K.J. Biomechanical effect of the configuration of screw hole style on locking plate fixation in proximal humerus fracture with a simulated gap: A finite element analysis. Injury 2016, 47, 1191-1195. [CrossRef] [PubMed]

16. Hsu, J.T.; Chang, C.H.; Huang, H.L.; Zobitz, M.E.; Chen, W.P.; Lai, K.A.; An, K.A. The number of screws, bone quality, and friction coefficient affect acetabular cup stability. Med. Eng. Phys. 2007, 29, 1089-1095. [CrossRef] [PubMed] 
17. Mingo-Robinet, J.; López-Durán, L.; Galetoe J.E.; Martinez-Cervell, C. Ankle fractures with posterior malleolar fragment: management and results. J. Foot Ankle Surg. 2011, 50, 141-145. [CrossRef]

18. Bartoníček, J.; Rammelt, S.; Klika, D.; Naňka, O.; Tuček, M.; Kostlivý, K.; Vaněček, V. Classification of posterior malleolar fractures in ankle fractures. Rozhl. Chir. 2018, 97, 52-59.

19. Huebner, E.J.; Iblher, N.; Kubosch, D.C.; Suedkamp, N.P.; Strohm, P.C. Distal tibial fractures and pilon fractures. Acta Chir. Orthop. Traumatol. Cech. 2014, 81, 167-176.

20. Assal, M.; Ray, A.; Stern, R. Strategies for surgical approaches in open reduction internal fixation of pilon fractures. J. Orthop. Trauma 2015, 29, 69-79. [CrossRef] [PubMed]

21. Hoekstra, H.; Rosseels, W.; Rammelt, S.; Nijs, S. Direct fixation of fractures of the posterior pilon via a posteromedial approach. Injury 2017, 48, 1269-1274. [CrossRef] [PubMed]

22. Hak, D.J. Anterolateral approach for tibial pilon fractures. Orthopedics 2012, 35, 131-133. [CrossRef] [PubMed]

23. MacLeod, A.R.; Serrancoli, G.; Fregly, B.J.; Toms, A.D.; Gill, H.S. The effect of plate design, bridging span, and fracture healing on the performance of high tibial osteotomy plates: An experimental and finite element study. Bone Jt. Res. 2018, 7, 639-649. [CrossRef] [PubMed]

24. Ingrassia, T.; Nigrelli, V.; Pecorella, D.; Bragonzoni, L.; Ricotta V. Influence of the Screw Positioning on the Stability of Locking Plate for Proximal Tibial Fractures: A Numerical Approach. Appl. Sci. 2020, 10, 4941. [CrossRef]

25. Yang, J.C.S.; Chen, C.F.; Lee, O.K. Benefits of opposite screw insertion technique in medial open-wedge high tibial osteotomy: A virtual biomechanical study. J. Orthop. Translat. 2020, 20, 31-36. [CrossRef]

26. Smith, W.R.; Ziran, B.H.; Anglen, J.O.; Stahel P.F. Locking plates: Tips and tricks. J. Bone Jt. Surg. Am. 2007, 89, 2298-2307. [CrossRef] [PubMed]

27. Ramlee, M.H.; Kadir, M.R.A.; Murali, M.R.; Kamarul, T. Finite element analysis of three commonly used external fixation devices for treating Type III pilon fractures. Med. Eng. Phys. 2014, 36, 1322-1330. [CrossRef] [PubMed]

28. Ghimire, S.; Miramini, S.; Richardson, M.; Mendis, P.; Zhang, L. Effects of dynamic loading on fracture healing under different locking compression plate configurations: A finite element study. J. Mech. Behav. Biomed. Mater. 2019, 94, 74-85. [CrossRef] [PubMed]

29. Benli, S.; Aksoy, S.; Havitcioğlu, H.; Kucuk, M. Evaluation of bone plate with low-stiffness material in terms of stress distribution. J. Biomech. 2008, 41, 3229-3235. [CrossRef]

30. Fan, Y.; Xiu, K.; Duan, H.; Zhang, M. Biomechanical and histological evaluation of the application of biodegradable poly-L-lactic cushion to the plate internal fixation for bone fracture healing. Clin. Biomech. 2008, 23, S7-S16. [CrossRef]

31. Izaham, R.M.A.R.; Kadir, M.R.A.; Rashid, A.H.A.; Hossain, M.G.; Kamarul, T. Finite element analysis of Puddu and Tomofix plate fixation for open wedge high tibial osteotomy. Injury 2012, 43, 898-902. [CrossRef] [PubMed] 